\section{Estudo fitoquímico de Zanthoxylum stelligerum (Turcz)}

\section{Érica Louvores de Oliveira'; Paulo do Carmo Freitas'; Maria Lenise da Silva Guedes²; Eudes da Silva Velozo" ${ }^{1 *}$}

${ }^{1}$ Laboratório de Pesquisa em Matéria Médica (LAPEMM), Faculdade de Farmácia, Universidade Federal da Bahia ${ }^{2}$ Instituto de Biologia, Universidade Federal da Bahia, 40170290, Salvador, BA, Brasil

lapemm@ufba.br

\section{Abstract}

The hexanic and methanolic extracts of roots and stem of Zanthoxylum stelligerum (Rutaceae), after chromatographic and phytochemical procedures, yelded the triterpene lupeol, the furanocumarin imperatorin and the benzophenathridine alkaloids dihidrocheleritrine and its probable product of oxidation. The structural determinations of these compounds were performed on basis of spectroscopic analysis as well as comparison with authentic samples.

No nordeste brasileiro são encontradas diversas espécies de Zanthoxylum (Rutaceae). Muitas delas são empregadas na medicina popular contra distúrbios inflamatórios ou infecções. Nas mais de 200 espécies pertencentes a este gênero são descritas a ocorrência de cumarinas, lignanas, flavonóides, alcalóides, alquilamidas insaturadas e óleos essenciais. Estas substâncias apresentam importantes propriedades farmacológicas tais como antitumorais, antibacterianas, antifúngicas, antiinflamatórias, anti-helmínticas, analgésicas e antiagregação plaquetária ${ }^{1,2,3,4,5,6,7,8}$.

O presente trabalho descreve o estudo fitoquímico do caule e raízes de $Z$. stelligerum (Turcz), espécie conhecida popularmente como laranjinha brava. A literatura consultada não fornece qualquer informação de estudos fitoquímicos sobre esta planta.

A identificação e determinação estrutural das substâncias isoladas de Z. stelligerum foram feitas com base na análise e interpretação dos espectros no IV, RMN ${ }^{1} \mathrm{H}$ e ${ }^{13} \mathrm{C}$ e espectrometria de massas e comparação destes dados com a literatura. As estruturas destas substâncias são mostradas na figura 1 .

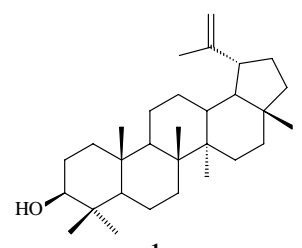

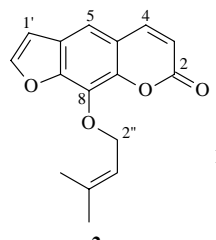

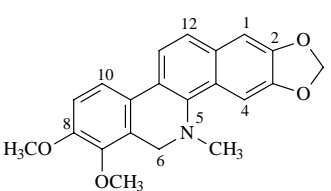

Figura 1. Estrutura das substâncias isoladas do caule e raízes de Zanthoxylum stelligerum.

A substância 1 foi identificada como lupeol. Foram obtidas $860 \mathrm{mg}$ desta substância, isoladas do extrato hexânico do caule e das raízes. Seus espectros de $\mathrm{RMN}{ }^{1} \mathrm{H}$ e ${ }^{13} \mathrm{C}$ são idênticos aos de um padrão.

A substância 2 foi caracterizada como a furanocumarina imperatorin. Obteve-se $200 \mathrm{mg}$ desta substância, do extrato hexânico das raízes. No seu espectro de RMN ${ }^{1} \mathrm{H}$ observa-se um par de dubletos $(2 \mathrm{H})$ em $\delta 7,75$ e $6,38(\mathrm{~J}=9,5 \mathrm{~Hz})$ e um singleto $(1 \mathrm{H})$ em $\delta 7,37$, indicativos de uma cumarina tri-substituída. A presença dos dubletos em $\delta 7,65(1 \mathrm{H})$ e $6,82(1 \mathrm{H}, \mathrm{J}=2,2$ $\mathrm{Hz}$ ) são diagnósticos de substituição por anel furano. Os sinais em $\delta 5,01(2 \mathrm{H}, \mathrm{d}, \mathrm{J}=7,1)$ e $\delta 1,75(\mathrm{~s}, 3 \mathrm{H})$ e $\delta 1,73(\mathrm{~s}, 3 \mathrm{H})$ indicam a presença de um grupamento O-prenila também substituindo o anel cumarínico. A análise e interpretação destes dados e dos espectros de $\mathrm{RMN}{ }^{13} \mathrm{C}$ e IV levaram a proposta da estrutura do imperatorin para esta substância.

O extrato hexânico das raízes forneceu também cerca de $660 \mathrm{mg}$ de um sólido que se precipita na presença dos reagentes de Dragendorff e Mayer indicando sua natureza alcaloídica (3). Seu espectro no IV apresenta bandas em: 3007 $\mathrm{cm}^{-1}$ relativa a deformação axial da ligação $\mathrm{C}-\mathrm{H}$ aromática e vibração de estiramento da ligação C-C aromática em $1600 \mathrm{~cm}^{-1}$. A espectrometria de massa revela o pico de $\mathrm{M}+\operatorname{com} \mathrm{m} / \mathrm{z} 349$ (100\%), compatível com a fórmula molecular $\mathrm{C}_{21} \mathrm{H}_{19} \mathrm{O}_{4} \mathrm{~N}$. No RMN ${ }^{1} \mathrm{H}$ observa-se, na região aromática, a presença de 6 sinais: dois singletos que integram para um hidrogênio cada e 4 dubletos, que integram para 4 hidrogênios, com J compatíveis com acoplamentos orto entre si. A análise do espectro de $\mathrm{RMN}{ }^{1} \mathrm{H}$ revela ainda a presença de um grupamento metilenodioxi, singleto (2H) em $\delta 6,05$, além de metoxilas em $\delta 3,89$ (s, 3H) e 3,93 (s, $3 \mathrm{H})$. A soma das integrais dos sinais mostra que esta substância possui realmente 19 átomos de hidrogênio. O RMN ${ }^{13} \mathrm{C}$ indica a presença de 21 átomos de carbono na estrutura, sendo 10 totalmente substituídos, 6 metínicos, 2 metilênicos e 3 metílicos. Estes dados estão de acordo com a estrutura da diidroqueleritrina para este alcalóide.

O isolamento de três classes diferentes de metabólitos nas raízes e caule comprova a variedade de substâncias que podem ser encontradas em espécies pertencentes ao gênero Zanthoxylum. Os alcalóides que ocorrem nesta espécie, possuem estruturas semelhantes a da sanguinarina, uma benzofenantridina incorporada em dentifrícios e enxaguatórios bucais por sua ação inibitória da formação da placa bacteriana. Estas substâncias candidatam esta planta como uma potencial fonte de matéria prima para a obtenção de antimicrobianos.

\section{Material e Métodos}

As raízes e caule de um espécime de Zanthoxylum stelligerum (Turcz) foram coletados no município de Mucugê (BA), em fevereiro de 1999. O exemplar coletado foi identificado pela Profa. Maria Lenise Guedes e sua exsicata, número 040919, está depositada no Herbário do Instituto de Biologia da UFBA. Os espectros de Ressonância Magnética Nuclear (RMN) foram obtidos em um espectrômetro marca Varian, modelo GEMINI 
300 operando a $300 \mathrm{MHz}$ para hidrogênio $\left({ }^{1} \mathrm{H}\right)$ e $75 \mathrm{MHz}$ para carbono $13\left({ }^{13} \mathrm{C}\right)$. Os solventes utilizados para obtenção dos espectros foram $\mathrm{CDCl}_{3}$ e CD3OD, tendo como referência interna tetrametilsilano (TMS). Os espectros de absorção na região do infravermelho (IV) foram obtidos em espectrofotômetro marca JASCO modelo VALOR III em pastilha de KBr e os espectros de massas num aparelho marca Shimadzu, modelo GS-MS-QP5000, equipado com detector CI-50 com impacto de elétrons de $70 \mathrm{eV}$. Após maceração e concentração do extrato hexânico das raízes ocorreu a precipitação de um sólido cristalino, formando uma fração oleosa e outra cristalina. Fracionou-se uma alíquota de 24,2 g da parte oleosa em coluna filtrante utilizando-se gel de sílica como fase estacionária e misturas de diclorometano e acetato de etila como eluentes. Uma alíquota da fração 1 desta coluna foi submetida a cromatografia em coluna de gel de sílica eluída com misturas de hexano e acetato de etila. Este procedimento levou ao isolamento das substâncias 1, 2 e 3. Uma alíquota de $1,7 \mathrm{~g}$ do precipitado foi solubilizado em hexano e submetido a partição com metanol. A fração solúvel em hexano foi submetida a cromatografia em coluna, tendo como eluentes misturas de $\mathrm{CHCl}_{3} / \mathrm{MeOH}$. Este procedimento levou ao isolamento da substância 3 que releva-se positivamente frente ao reagente de Dragendorff. Foi efetuada uma partição (hexano/ metanol) de uma alíquota de 4,8 g do extrato hexânico do caule. A fração hexânica foi submetida a cromatografia em coluna, utilizando-se como eluente misturas de hexano/acetato de etila. Este procedimento levou ao isolamento de um sólido que reage positivamente para o teste de Lieberman-Buchart ${ }^{1}$.

\section{Agradecimentos}

Agradecemos ao PIBIC - CNPq, pela bolsa de Iniciação Científica concedida, e à Universidade Federal da Bahia, pelo espaço físico concedido para a realização da pesquisa.

\section{Referências}

${ }^{1}$ Moura, N.F., Ribeiro, H.B., Machado, E.C.S., Ethur, E.M., Zanatta, N.F.(1997). Benzophenanthridine alkaloids from Zanthoxylum rhoifolium .Phytochemistry, 46: (8), 1443-1446

${ }^{2}$ Swinehart, J.A ., Stermitz, F.R. (1980). Bishordeninyl terpene alkaloids and other constituents of Zanthoxylum culantrillo and Zanthoxylum coriaceum . Phytochemistry, 19 : (6), 12191223

${ }^{3}$ Facundo, V.A ., Morais, S.M., Braz, R.F., Matos, F.J.A., Souza, R. T. (1997). Estudo químico de plantas potencialmente bioativas do nordeste brasileiro: Zanthoxylum syncarpum Tull . Revista Brasileira de Farmácia, 78: (3), 57-59

${ }^{4}$ Kalia, N.K., Singh, B., Sood, R.P. (1999). A new amide from Zanthoxylum armatum. J. Nat. Prod., 62 (2), 311-312

${ }^{5}$ Bastos, J.K., Gottlieb, O.R., Sarti, S.J. (1996). Isolation os lignans and sesquiterpenoids from leaves of Zanthoxylum naranjillo. Nat. Prod. Lett. 9: (1), 65-70

${ }^{6}$ Chen, I., Wu, S. ,Lin, Y., Tsai, I. , Seki, H., Ko, F. (1994). Dimeric 2-quinolone alkaloid and antiplatelet aggregation constituents of Zanthoxylum simulans . Phytochemistry, 36: (1), 237-239

${ }^{7}$ Moura, N.F.,Giacomelli, S.R., Machado, E. C. (1998). Antibacterial activity of Zanthoxylum rhoifolium . Fitoterapia 69: (3), 271-272

${ }^{8}$ Navarrete, A., Hong, E. (1996). Anthelmintic properties of alphasanshool from Zanthoxylum liebmannianum. Planta Med. 62: (3), 250-251 